\title{
HARMONISED APPROACH TO THE ASSESSMENT OF MAJOR ACCIDENT RISKS IN THE FRAMEWORK OF SEVESO II DIRECTIVE: CASE STUDY ON ARAMIS METHODOLOGY APPLICATION
}

The goal of the contribution is ARAMIS methodology presentation by a specific case study on the assessment of risks of major accidents in an industrial establishment unclassified within the scope of the SEVESO II Directive, but in spite of this the enterprise that represents a significant risk of major accident to employees and neighbouring inhabitants. At present, any legislative pressure is not being produced on the operators of such unclassified sources to make risk analyses and contribute thus to major accident prevention and risk reduction. The ARAMIS methodology was developed as a project within the 5th EC Framework Programme in a team of known European workplaces with the aim to prepare a harmonised methodology for risk assessment especially for the purpose of meeting the conditions of the SEVESO II Directive. A subgoal of the submitted analysis was to test the applicability of the new ARAMIS methodology to the conditions of unclassified risk sources.

Key words: ARAMIS, risk assessment, SEVESO II, major accident prevention

\section{Introduction}

The ARAMIS methodology ("Accidental Risk Assessment Methodology for IndustrieS in the framework of the SEVESO II directive") was developed as a project within the $5^{\text {th }}$ EC Framework Programme (Energy, Environment and Sustainable Development Programme) in the period from 2002 to 2004. Members of the team were prestigious European institutes, such as INERIS, EPSC, JRC, TU Delft, etc. The ARAMIS project proposes a harmonised methodology for risk assessment aimed at diminishing uncertainties and result variability and at including the evaluation of risk management efficiency into the analysis. ARAMIS should be understood as a comprehensive tool for efficient risk identifi-

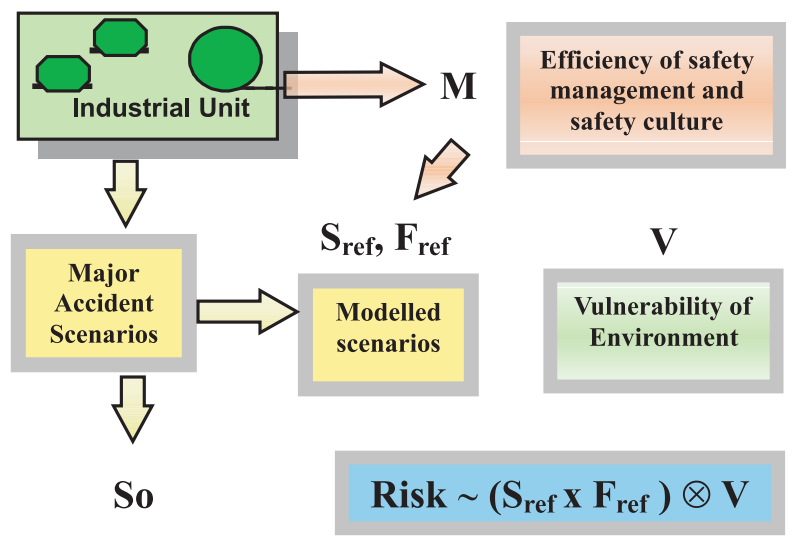

Fig. 1 Summary diagram of the ARAMIS methodology [2] cation and analysis with many steps prepared in advance and recommended. The common procedure of ARAMIS methodology is summarised in Figure 1.

The whole procedure may be divided into three basic steps, the outputs of which are relevant indexes as follows:

1. the assessment of consequence severity ( $\mathrm{S}$ - severity index),

2. the assessment of the efficiency of risk management (M management index),

3. the assessment of vulnerability of the surrounding environment ( $\mathrm{V}$ - vulnerability index).

All the indexes may be assessed separately, but primarily the indexes $\mathrm{S}$ and $\mathrm{M}$ are considerably interconnected in the selection of reference accident scenarios and the calculation of consequence severity, when effective measures to reduce risks may affect the frequency of accidents and/or to limit the extent of accident consequences.

The detailed description of the ARAMIS methodology is presented in a form of a case study in the enterprise unclassified within the scope of the SEVESO II Directive (or the Czech Act No. 353/1999 of the Code on major accident prevention, as subsequently amended). In spite of this, in this industrial establishment producing drinks, several significant hazardous substances are present. By agreement with the enterprise management, any name of the enterprise is not presented; however, all given data correspond to practical conditions in the enterprise not subject to the legal force of the Act No. 353/1999 of the Code.

\footnotetext{
* Aleš Bernatík, Šárka Horehledoová, Petra Nevrlá

VŠB-Technical University of Ostrava, Faculty of Safety Engineering, Lumírova 13, 70030 Ostrava-Vy̌škovice, Czech Republic,

Tel: +420 597322 833, fax: +420 597322 982, E-mail: ales.bernatik@vsb.cz
} 
At present, the selection of those pieces of equipment, for safety of which the documentation in the area of major accident prevention is required, is being exercised on the basis of limit amounts of hazardous substances given in the Act No. 353/1999 of the Code. This rather simple procedure according to the cumulative formula brings advantages and also disadvantages. On the one hand, it decides unambiguously about placing the enterprise into the group A or B; however, on the other hand it does not give any information on a following risk to the environment. In some cases, the source of risk with an under-limit amount of hazardous substances located, e.g. in a densely populated area can represent a greater hazard than a rather large source with an over-limit amount situated outside residential zones.

That is why one of the goals of the submitted contribution is to increase awareness on these unclassified risk sources, because risk perception is one of the main conditions of accident prevention. The next objective is a proposal for suitable methods of risk assessment for these unclassified risk sources - in this case the testing of ARAMIS methodology applicability. As risk sources not subject to the legal effect of the Act No. 353/1999 of the Code on major accident prevention, e.g. food-processing complexes (breweries, dairies, meat combines), sports facilities (ice-stadiums, swimming pools) and further water treatment plants, storage areas of pressure vessels, pumping stations and storage tanks of LPG were identified.

\section{MIMAH method}

To determine the $\mathrm{S}$ index, or reference scenarios of accidents it is necessary to do two partial assessments according to the methods for the identification of risk sources designed by the ARAMIS project - MIMAH and MIRAS methods.

The goal of MIMAH is to identify potential scenarios of accidents that may occur in the industrial process. MIMAH defines the maximum dangerous potential in the piece of equipment. In this phase of assessment the scenarios are to be taken as the worst cases that can occur without considering any safety measures (including safety management).

\subsection{Identification of Potential Risk Sources in the Enterprise}

On the basis of information acquired from the inspection of the enterprise, a list of sources of risks of major accidents, in which hazardous chemical substances are manipulated, produced, used, etc. was prepared. Hazardous substances are designated by one or more R-phrases according to the official classification of hazardous substances. Results of this step are arranged into Table 1.

For the purpose of the identification of risk sources, 16 types of equipment are defined by this method; in our case study they are as follows: EQ3 - storage of fluids in small packages, EQ4 pressure storage, EQ6 - atmospheric storage.

\subsection{Selection of Major Risk Sources}

This procedure is based on the VADE MECUM method from Belgium. Pieces of equipment containing hazardous substances are selected for the next assessment, if the quantity of hazardous substances is greater than the defined threshold quantity. This threshold quantity is determined depending upon the hazardous properties of the substances, their physical states and their position in relation to other hazardous pieces of equipment.

As a result of this part of the ARAMIS methodology (method of the selection of major risk sources), the following three major sources were selected for the next assessment: engine room for cooling (source No.1), LPG pumping station consisting of 2 storage tanks (source No. 2) and LFO storage unit (source No. 6). In the next steps, these sources will be assessed in accordance with the MIMAH method.

\subsection{Association of a Critical Event}

With each selected risk source, a critical event must be associated (CE - Critical Event). The critical event is defined as a leak of the content (LOC - Loss of Containment) of liquids from the piece of equipment, or for solid substances more specifically as

List of potential risk sources identified

Table 1

\begin{tabular}{|c|c|c|c|c|}
\hline $\begin{array}{c}\text { Hazardous } \\
\text { substance }\end{array}$ & R-phrase classification & $\begin{array}{c}\text { Amount } \\
(\mathrm{kg})\end{array}$ & Name of equipment + type & $\begin{array}{c}\text { Physical state of } \\
\text { substance }\end{array}$ \\
\hline 1. Ammonia & T, N R10-23-50 & 22,000 & engine room for cooling: EQ4 & two-phase \\
\hline 2. Propane & F+ R12 & 4900 & LPG pumping station: EQ4 & two-phase \\
\hline 3. Acetylene & F+ R5-6-12 & 110 & pressure vessels: EQ3 & gas \\
\hline 4. Oxygen & O R8 & 179 & pressure vessels: EQ3 & liquid \\
\hline 5. Diesel oil* & Xn R40 & 3200 & locotractor depot: EQ3 & liquid \\
\hline 6. Light fuel oil* & Xn R40 & 233,000 & LFO storage unit: EQ6 & \\
\hline
\end{tabular}

*These substances were included into assessment although they are not classified as flammable substances. 
a change in the physical state (LPI - Loss of Physical Integrity) The MIMAH method presupposes 12 critical events. For the association of the critical event with the major risk source, the following two matrices are used:

- the matrix of the type of equipment and 12 potential critical events

- the matrix of the physical state of substances and 12 potential critical events.

The result of this part of MIMAH method is the association of the following critical events with the selected risk sources:

Source No. 1 - Engine room for cooling:

CE8 - Leak from the liquid pipe

Source No. 2 - LPG pumping station:

CE10 - Catastrophic rupture

Source No. 6 - LFO storage unit:

CE7 - Breach on the shell with liquid leak

\subsection{Construction of "Bow-Tie" Diagram for Each Critical Event}

The MIMAH methodology ended with the building of a complete bow-tie diagram for each selected piece of equipment. The bow-tie diagram is built by the association of the critical event with the corresponding fault tree on the left and the corresponding event tree on the right (see Fig. 2). These bow-tie diagrams must be understood as scenarios for major accident without considering any installed safety measures. The evaluation of safety systems forms a basis of MIRAS methodology application.

The result of MIMAH in the case study is the construction of three bow-tie diagrams for selected critical events that will be further assessed in the MIRAS part. With reference to the size of the diagram, they cannot be presented here.

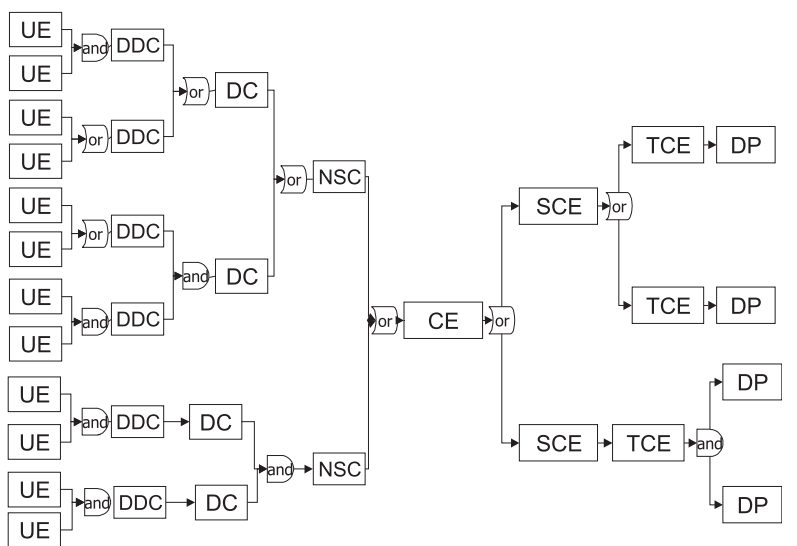

Fig. 2 A common 'bow-tie' diagram for one critical event [3] Notes: UE - Undesirable Event, DDC - Detailed Direct Cause, DC - Direct Cause, NSC - Necessary and Sufficient Condition, CE - Critical Event, SCE - Secondary Critical Event, TCE - Tertiary Critical Event, DP - Dangerous Phenomena

\section{MIRAS method}

The objective of MIRAS is to select reference scenarios from the scenarios identified in the MIMAH part. The method rests on studying the influence of elements of safety and risk management on the scenarios selected in MIMAH. The reference accident scenarios (RAS) represent a real hazardous potential of the piece of equipment after considering safety systems, including management (see Fig. 3). In the MIRAS methodology, safety systems installed on the piece of equipment, the safety management system, the frequency of accident occurrence and the possible consequences of the accident are considered.

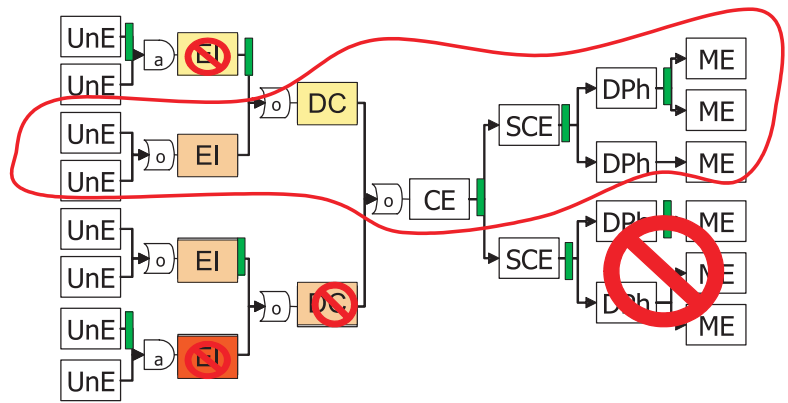

Fig. 3 Identification of reference accident scenarios - MIRAS [3]

Notes: UnE - Undesirable Event, EI - Initiating Event, DC - Direct

Cause, CE - Critical Event, SCE - Secondary Critical Event, DP - Dangerous Phenomena, ME - Major Event

\subsection{Determination of the Frequency of a Critical Event by Fault Tree Analysis}

This step is divided into 4 parts designated A - D. A: Determination of frequencies of initiating events B: Determination of safety barriers in the fault trees C: Assessment of the performances of safety barriers D: Calculation of the frequency of the critical event

The output of the case study is formed by three fault trees with the determined frequencies of critical events; with reference to the size of the diagram, the fault tree for the risk source No. 2 - catastrophic rupture of LPG storage tanks (Figure 4) is illustrated in the next page as an example.

The result of this part of the MIRAS methodology is formed by the frequencies of critical events after taking into account safety barriers in the fault trees.

- For CE8 - great leak of ammonia from the pipe $-1.3 \times 10^{-5}$ / /year

- For CE10 - catastrophic rupture of the LPG storage tank $2.1 \times 10^{-6} /$ year

- For CE7 - large leak of LFO through the breach on the storage shell $-1.4 \times 10^{-5} /$ year

In the case of the critical event frequency lower than $10^{-7} /$ /year, there is no need to apply any subsequent steps. 
KaMnNlkacle

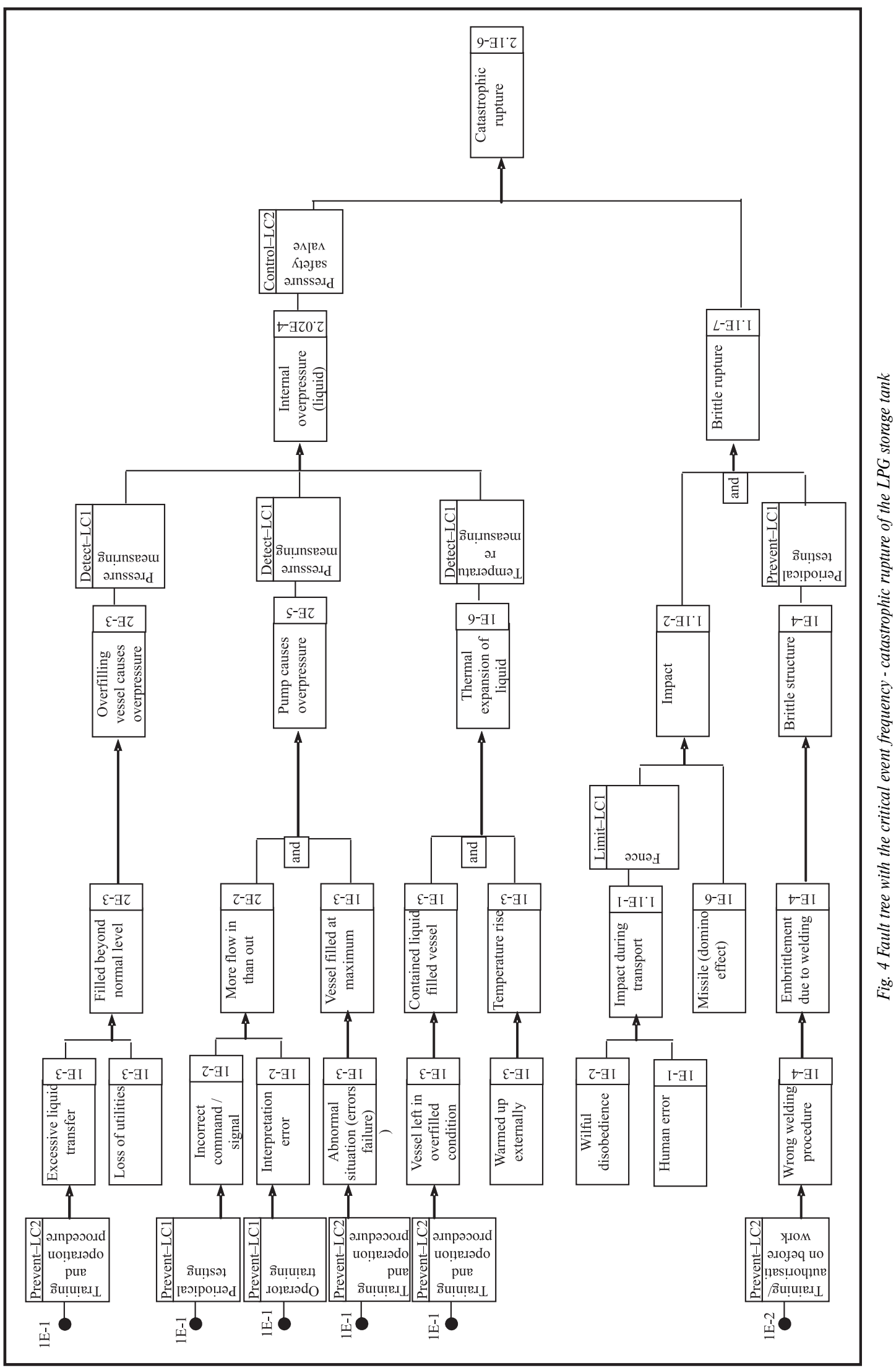

KOMUNIKÁCIE / COMMUNICATIONS 


\subsection{Determination of Frequencies of Dangerous Phenomena}

The objective of this step is to obtain the frequencies of all dangerous phenomena of selected critical events. The procedure is based on taking into account critical barriers in the event trees that may decrease the frequency or consequences of dangerous phenomena. From the results for the 3 selected critical events merely the event tree for the risk source - LPG storage tanks is illustrated as an example (Figure 5).

\subsection{Evaluation of the Classes of Consequences of Dangerous Phenomena}

At this phase of the methodology it is necessary to carry out the rough evaluation of consequences of dangerous phenomena. This qualitative evaluation of consequences is based on the classification of dangerous phenomena into 4 classes of consequences (C1 - C4), where the class $\mathrm{C} 4$ means the most severe effects on the health of people or on the environment. For particular dangerous phenomena the MIRAS methodology offers pre-defined classes of consequences that may be modified according to the efficiency of barriers limiting the leaking quantity or the effect of dangerous phenomena. Resulting classes of consequences are summarised in Table 2.

\subsection{Selection of the Reference Accident Scenario}

Reference scenarios are selected by means of a tool - risk matrix (see Figure 6).
Frequencies and classes of consequences of dangerous phenomena

\begin{tabular}{|c|l|r|c|}
\hline No. & \multicolumn{1}{|c|}{ Dangerous phenomenon } & Frequency & $\begin{array}{c}\text { Class of } \\
\text { consequences }\end{array}$ \\
\hline \multirow{2}{*}{1.} & 1a) Toxic cloud limited & $6.5 \times 10^{-6} /$ year & $\mathrm{C} 2$ \\
\cline { 2 - 4 } & 1b) Toxic cloud full & $5.2 \times 10^{-6} /$ year & $\mathrm{C} 3$ \\
\cline { 2 - 4 } & 1c) Environmental damage & $1.3 \times 10^{-6} /$ year & $\mathrm{C} 2$ \\
\hline \multirow{2}{*}{2.} & 2a) Poolfire & $2.1 \times 10^{-7} /$ year & $\mathrm{C} 2$ \\
\cline { 2 - 4 } & 2b) VCE & $1.4 \times 10^{-6} /$ year & $\mathrm{C} 3$ \\
\cline { 2 - 4 } & 2c) Flashfire & $1.4 \times 10^{-6} /$ year & $\mathrm{C} 3$ \\
\cline { 2 - 4 } & 2d) Fireball & $1.4 \times 10^{-6} /$ year & $\mathrm{C} 4$ \\
\hline \multirow{2}{*}{6.} & 6a) Poolfire & \multicolumn{2}{|c}{} \\
\hline
\end{tabular}

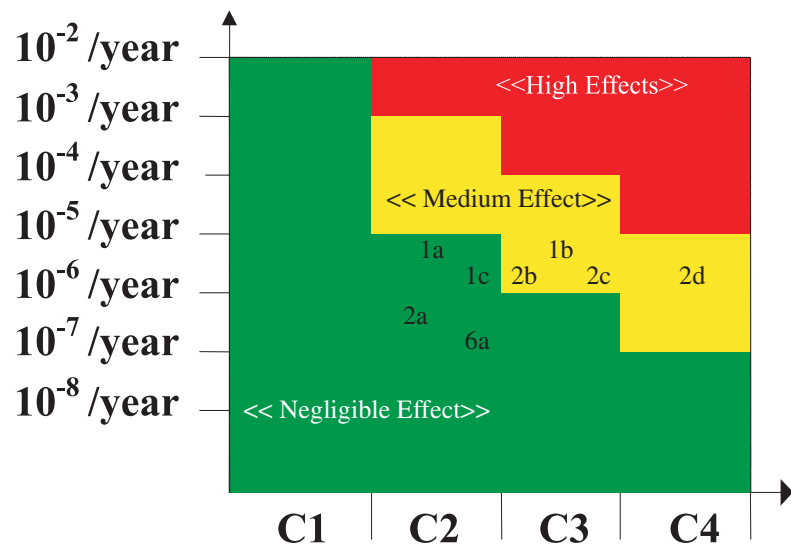

Fig. 6 Risk matrix with marked results

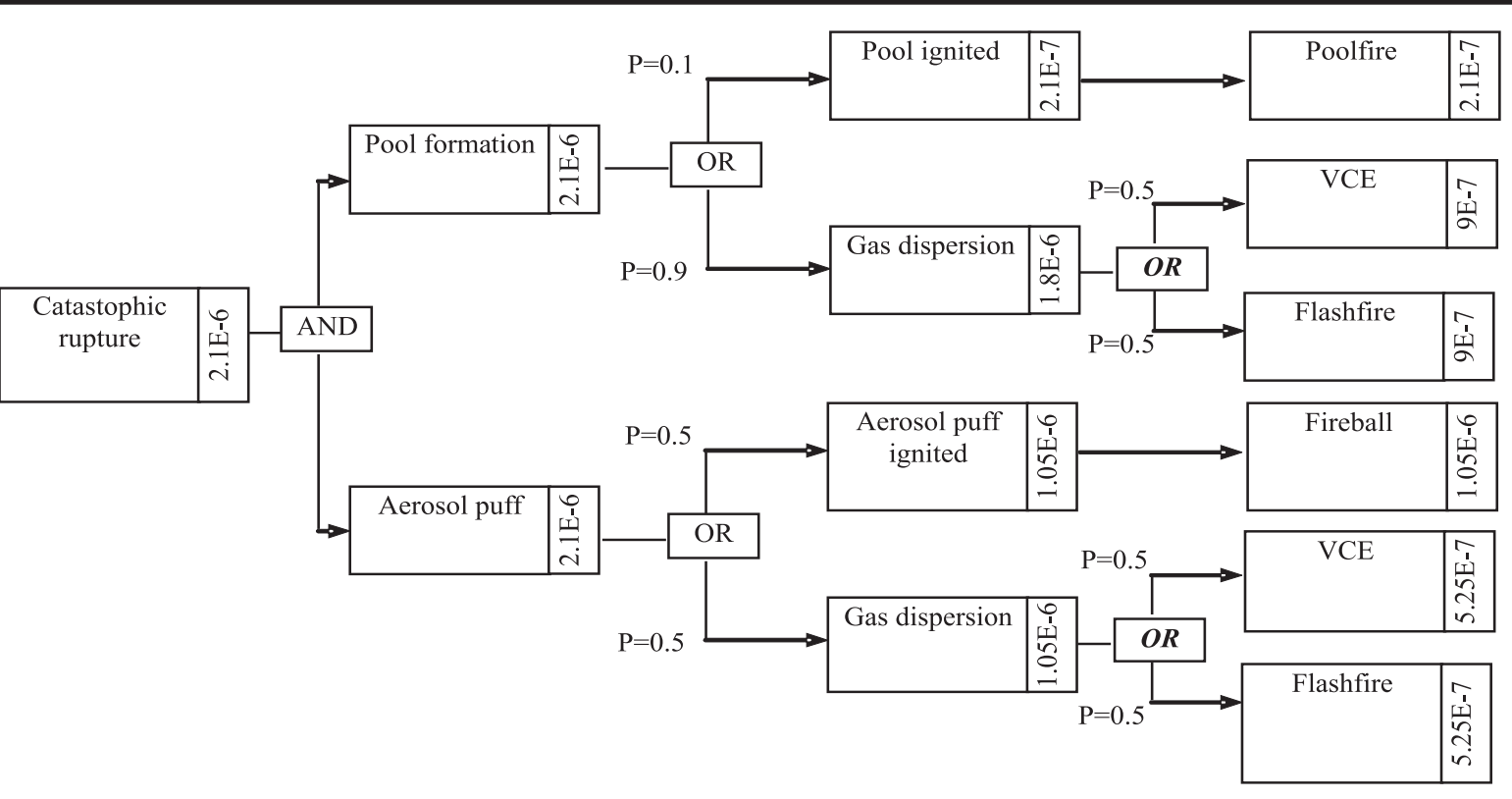

Fig. 5 Event tree with dangerous phenomena frequencies - rupture of the LPG storage 
It is necessary to note that the risk matrix does not decide about risk acceptability in this phase of the methodology, but that it merely selects the reference accident scenarios that are further modelled for the purpose of severity calculation.

\section{S Index}

The goal of this part of the ARAMIS methodology is the determination of severity of reference accident scenarios by means of proposed parameters. Just the proposal for threshold values of specific effects of accidents is another significant benefit of the methodology, because any recommended values do not exist uniformly in the European Union yet. Following Table 3 summarises
MIRAS, in the industrial establishment unclassified under the SEVESO II Directive. The objective was to test the applicability of the methodology to such types of enterprises. The following conclusions may be drawn:

- ARAMIS enables the assessment of unclassified sources of risks.

- In many steps it facilitates, by pre-defined data, the procedure of detailed risk assessment.

- The making of the analysis is, however, demanding from the professional as well as temporal point of view.

For this reason, other works will be concentrated on considering a possibility of a simplification of the ARAMIS methodology for the purposes of unclassified sources of risk. Results obtained continuously from risk assessment indicate a necessity to manage

Defining threshold values for various levels of consequences [1]

Table 3

\begin{tabular}{|c|c|c|c|c|c|c|}
\hline Level of effects & $\begin{array}{c}\text { Radiation } \\
\left(\mathrm{kW} / \mathrm{m}^{2}\right)\end{array}$ & $\begin{array}{c}\text { Instantaneous } \\
\text { radiation }\end{array}$ & $\begin{array}{c}\text { Blast } \\
(\mathrm{mbar})\end{array}$ & $\begin{array}{c}\text { Missiles } \\
(\%)\end{array}$ & Toxic effects ${ }^{(1)}$ & Description \\
\hline $\mathrm{d} 1$ & $<1.8$ & $0-1 / 6 \mathrm{LFL}$ & $<30$ & 0 & $<$ TEEL-1 & Small or non effects \\
\hline $\mathrm{d} 2$ & $1.8-3$ & $1 / 6-1 / 3 \mathrm{LFL}$ & $30-50$ & & TEEL-1 - TEEL-2 & Reversible effects \\
\hline $\mathrm{d} 3$ & $3-5$ & $1 / 3-1 / 2 \mathrm{LFL}$ & $50-140$ & & TEEL-2 - TEEL-3 & Irreversible effects \\
\hline $\mathrm{d} 4$ & $>5$ & $\geq 0.5 \mathrm{LFL}$ & $>140$ & 100 & $>$ TEEL-3 & $\begin{array}{c}\text { Fatal consequences } \\
\text { or domino effects }\end{array}$ \\
\hline
\end{tabular}

(1) TEEL -Temporary Emergency Exposure Limits - defined concentrations for an hour's exposure, identical with ERPG values, available for more than 2000 substances

Results of the distance of the range of dangerous phenomena for CE10 - LPG storage tanks

Table 4

\begin{tabular}{llll|}
\hline Critical event & CE10 & Frequency & $2.1 \mathrm{E}-06$ \\
\hline
\end{tabular}

\begin{tabular}{|l|c|c|c|c|c|}
\hline Dang. phenomeno & & d1 & d2 & d3 & d4 \\
\hline VCE & 2b & 260 & 165 & 75 & 45 \\
\hline Flashfire & 2c & 72 & 72 & 68 & 35 \\
\hline Fireball & 2d & 430 & 330 & 255 & 195 \\
\hline
\end{tabular}
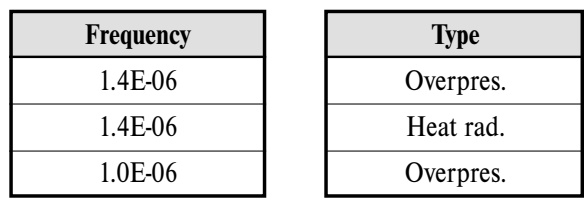

values corresponding to four levels of consequences. Calculations of distance (radius of affected area) for specific levels were executed by the Dutch model EFFECTS 5.5. Following Table 4 gives an example of results in the form of distances (in meters) for specific levels of consequences $\mathrm{d} 1-\mathrm{d} 4$ and for each dangerous phenomenon selected as a reference accident scenario. The type of consequences expresses one of the four possible serious effects of the accident (heat radiation, overpressure, fragments, toxic effects).

\section{Conclusion}

The case study describes the application of the ARAMIS methodology, especially of its introductory part, MIMAH and the risks and those unclassified sources of risks that at present are not included in legal regulations from the point of view of prevention, but in spite of this they can represent significant risks of major accidents.

This contribution was prepared as a part of dealing with the grant project GAČR 104/02/D070 titled in English "Design of a Methodology for the Assessment of Major-Accidents Risks in the Context of the European IPPC Directive and the Amendment to the SEVESO II Directive". The goal of the grant project is the creation of a methodical procedure for the management of risks of unclassified risk sources. 
KOMNIIKaCle

\section{References}

[1] DelVOSALlE, C., FIEVEZ, C., PIPART, A.: ARAMIS Project, Deliverable D.1.C., 2004.

[2] HOURTOLOU, D., SALVI, O.: ARAMIS project: Achievement of the Integrated Methodology and Discussion about Its Usability from the Case Studies Carried Out on Real Test Seveso II Sites, Loss Prevention and Safety Promotion; Proc. Intern. Symp., Prague, 1-3 June 2004.

[3] NEVRLÝ, V.: Comparison of Methods of Major Accident Risk Assessment, Diploma thesis, VŠB-TUO, 2004.

[4] http://aramis.jrc.it 